\title{
RECENSIÓN DEL LIBRO: GÓMEZ GARCIA, JUAN ANTONIO: DERECHO Y ANALOGÍA. ESTUDIOS DE HERMENÉUTICA JURÍDICA. MADRID: EDITORIAL UNED, 2017. 120 PÁGINAS. ISBN ELECTRÓNICO: 978-84-362-7283-3
}

\section{Isabel Beltrá Villaseñor ${ }^{1}$}

\section{Resumen}

El presente trabajo constituye una reseña crítica del libro mencionado en el título.

Palabras clave: Filosofía del Derecho; Teoría del Derecho; Hermenéutica jurídica; Hermenéutica analógica

El presente libro es una compilación de siete trabajos sobre hermenéutica jurídica analógica, la mayoría inéditos, y unos pocos ya publicados en diversos libros colectivos y revistas científicas, tanto españolas como mexicanas. Como es sabido, es fundamentalmente en el ámbito académico de México y de España donde la hermenéutica analógica, en su aplicación específica al Derecho, ha experimentado una mayor atención y desarrollo, merced, sobre todo, a que la hermenéutica analógica es resultado directo del agudo y fecundo pensamiento de su fundador, el filósofo mexicano Mauricio Beuchot, y también a que el espacio académico donde (aparte de México) ha recibido una más viva acogida, es la comunidad iusfilosófica española, especialmente en el seno del Departamento de Filosofía jurídica de la Facultad de Derecho de la UNED y en la Universidad de Valladolid, donde se celebran anualmente unas Jornadas monográficas sobre esta filosofía hermenéutica.

El autor del libro, el profesor de Filosofía del Derecho de la UNED Juan Antonio Gómez García, es un investigador muy oportuno para llevar a cabo su redacción, puesto que atesora una dilatada trayectoria científica y académica, no solo en el ámbito específico de la hermenéutica analógica (de hecho es Investigador Honorario del Seminario de Hermenéutica de la Universidad Nacional Autónoma de México, fundado y dirigido por el propio Mauricio Beuchot), sino también porque cuenta en su haber con numerosas publicaciones especializadas sobre Teoría y Filosofía del Derecho en general, y sobre hermenéutica filosófica y jurídica, siendo también es conocido por su amplia obra sobre Derecho y Cine, tanto en España como en toda Hispanoamérica. De hecho, este libro contiene la práctica totalidad de la producción del autor, en relación con las aplicaciones de la hermenéutica

\footnotetext{
${ }^{1}$ Licenciada en Filosofía y Master en Estudios Avanzados de Filosofía por la Universidad Complutense de Madrid - UCM. Doutoranda en Filosofía Medieval en la Universidad Complutense de Madrid - UCM.E-mail: jagomez@miradas.net
} 
analógica a los estudios iusfilosóficos y jurídicos.

La razón de ser y el propósito esencial de esta obra se puede resumir en la siguiente idea: proponer una recuperación y una reivindicación de la ontología jurídica, en el ámbito de la Filosofía del Derecho, mediante la hermenéutica analógica. En consecuencia, en tanto que ontológico, se trata de un libro que pretende ser eminentemente iusfilosófico, al ir más allá de una consideración meramente metodológica de la cuestión de la analogía en relación con el Derecho (tema habitual de la Teoría del Derecho), quedando así ésta integrada implícitamente, en cuanto metodología jurídica operada a partir de los presupuestos de una hermenéutica jurídica analógica.

Ciertamente, es partiendo de la hermenéutica desde donde puede (y debe) rescatarse hoy abiertamente la cuestión ontológica en la Filosofía actual, puesto que constituye el lugar desde el cual procede, en puridad y con el máximo de potencial comprensivo y explicativo, retomar tal cuestión. Desde luego, esto es plenamente extrapolable al Derecho, ámbito en el cual la hermenéutica filosófica ha estado aún más olvidada que en otros, debido (entre otros muchos factores) al incontestable imperio de la cultura jurídica iuspositivista durante los dos últimos siglos. En efecto, ésta casi exclusiva preponderancia del iuspositivismo, constituye la causa principal de tal desinterés por la hermenéutica filosófica, sin olvidar tampoco el ofuscamiento que la ontología jurídica ha experimentado, incluso por parte de perspectivas que, de entrada, fungen iusfilosóficamente de ontológicas (caso de los iusnaturalismos fundamentalistas, por ejemplo), y que, al igual que los iuspositivismos, han terminado incurriendo en visiones excesivamente univocistas sobre lo jurídico, participando así totalmente de la dialéctica frente al iuspositivismo que, ab initio, pretendían refutar. Así pues, se nos antoja muy saludable una perspectiva como la que se propone en este libro, por lo que tiene de sugestiva y de potencialmente renovadora en el ámbito de la Filosofía y la Teoría jurídica.

Aun pareciendo a primera vista demasiado ambicioso y supuestamente rupturista, sin embargo, este programa iusfilosófico se realiza con el fin de rescatar planteamientos y líneas de desarrollo clásicos de la Filosofía jurídica, tratando de renovarlos y actualizarlos, en atención a la presente situación de cambio profundo de las estructuras y las categorías jurídicas contemporáneas, y a su consiguiente crisis, lo cual obliga a pensar y repensar lo jurídico según los nuevos tiempos y demandas. Bajo los postulados fundamentales de la hermenéutica analógica y teniendo permanentemente presente, pues, la analogía como instrumento metodológico referencial, el autor lleva a cabo su empresa de acuerdo con la clásica tradición aristotélica, en virtud de la cual la analogicidad constituye la auténtica y profunda condición ontológica del ser jurídico. De esta manera, la hermenéutica jurídica analógica, según Juan Antonio Gómez, puede contribuir a repensar y recomponer la ley jurídica y la sistematicidad de los Derechos actuales, tratando de no traicionar tal condición sustancial.

En consecuencia, teniendo como presupuesto tal diagnóstico, la presente colección de estudios ofrece 
razones y bases para fundar una comprensión de lo jurídico desde la ontología y, en último término, desde el pensamiento analógico, de tal modo que puedan derivarse desarrollos más concretos en ámbitos como la Ética jurídica, la teoría y la práctica de los derechos humanos, la Teoría del Derecho, la metodología jurídica, la Dogmática jurídica, la Teoría de la interpretación y de la argumentación jurídicas, y más específicamente, en relación con las distintas ramas e instituciones del derecho. Todo ello sin dejar de lado la trascendental cuestión de la fundamentación de lo político en el contexto actual de las democracias deliberativas, al abordar monográficamente, en el último estudio, una de sus principales filosofías, como es la teoría de la acción comunicativa de Jürgen Habermas.

Estamos, pues, ante un libro de auténtica Filosofia del Derecho, pues se plantea la cuestión de lo jurídico en un plano genuinamente filosófico, apelando a su fundamentación ontológica primera. Esto no es habitual hoy en la disciplina, más bien apegada a ámbitos como la Teoría del Derecho, o a la Ética y Deontología jurídicas; y en este sentido, la presente compilación de estudios contribuye, de manera muy profunda e interesante, a reavivar y a enriquecer el debate filosófico sobre los fundamentos ontológicos de lo jurídico, ofreciendo ideas, perspectivas y herramientas que pueden resultar provechosas y muy atractivas para afrontar la ineludible tarea de pensar lo jurídico hoy.

Finalmente, es de agradecer que el libro haya sido editado en formato de e-book, en una edición muy cuidada y muy funcional por parte de la UNED, sin duda el más adecuado para nuestros tiempos digitales.

\section{REVIEW OF THE BOOK: GÓMEZ GARCIA, JUAN ANTONIO: LAW AND ANALOGY. STUDIES OF LEGAL HERMENEUTICS}

\section{Abstract}

The present work constitutes a critical review of the book mentioned in the title.

Keywords: Philosophy of Law; Law theory; Legal hermeneutics; Analogue hermeneutics

Trabalho enviado em 16 de novembro de 2017.

Aceito em 24 de junho de 2018. 